\title{
Correction to: Elucidating the therapeutic activity of selective curcumin analogues: DFT-based reactivity analysis
}

\section{Rituparna Hazarika $^{1} \cdot$ Bulumoni Kalita $^{1}$}

Published online: 28 April 2021

(C) Springer Science+Business Media, LLC, part of Springer Nature 2021

\section{Correction to: Structural Chemistry} https://doi.org/10.1007/s11224-021-01745-7

Typographical error appears in equation (3) in the manuscript. The corrected equation (3) is presented in this erratum.

$\eta=\left(\frac{\partial^{2} E}{\partial^{2} N}\right)_{V(\vec{r})}=\left(\frac{\partial \mu}{\partial N}\right)_{V(\vec{r})}$

Publisher's note Springer Nature remains neutral with regard to jurisdictional claims in published maps and institutional affiliations. 10.1007/s11224-021-01745-7

\footnotetext{
Bulumoni Kalita

bulumoni@dibru.ac.in

1 Department of Physics, Dibrugarh University,

Dibrugarh, Assam 786004, India
} 